\title{
Pemberdayaan Kemandirian Pangan Berbasis Urban Farming di Kawasan Padat Penduduk Kota Surakarta Jawa Tengah
}

\author{
Empowerment of Food Independence Based on Urban Farming in the Densely Populated Area of \\ Surakarta City Central Java
}

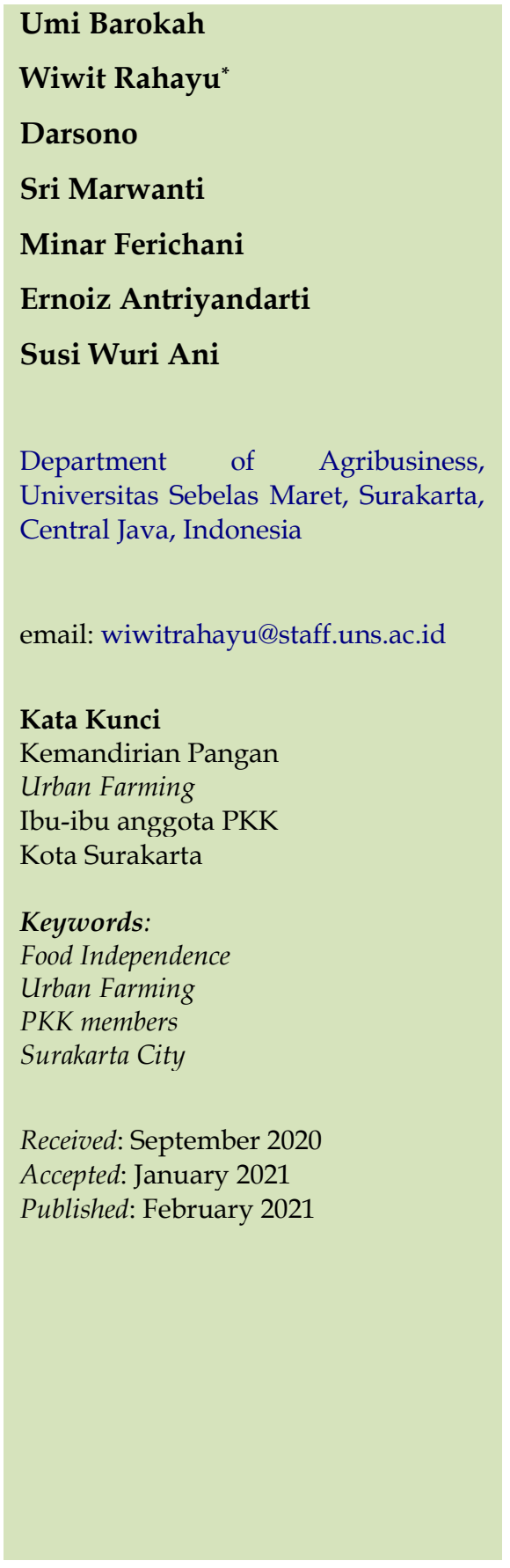

\begin{abstract}
Abstrak
Salah satu masalah yang dihadapi dalam penyediaan pangan dari produksi pada rumah tangga perkotaan adalah keterbatasan lahan. Hal ini juga terjadi di Kota Surakarta. PKK RT 03 RW XVI, Gendingan Kelurahan Jebres Kecamatan Jebres Kota Surakarta merupakan kelompok ibu-ibu yang tinggal di pemukiman padat penduduk. Permasalahan yang dihadapi rumah tangga dalam pemenuhan pangan keluarga adalah ketergantungan pada pembelian karena keterbatasan lahan untuk produksi pangan. Salah satu solusi untuk mengatasi masalah ini adalah dengan mengembangkan kegiatan pertanian perkotaan untuk mendukung kemandirian pangan. Hanya saja ibu-ibu anggota PKK belum memiliki pengetahuan tentang pertanian perkotaan (urban farming), cara menerapkannya dan sarana prasarananya terbatas. Oleh karena itu, kegiatan pengabdian ini dilakukan untuk menyelesaikan masalah tersebut dengan melakukan penyuluhan dan pelatihan urban farming, pemberian bantuan sarana produksi berupa benih, bibit, polibag, wallbag, pot, dan media tanam. Selain itu juga dilakukan pendampingan penerapan urban farming pada ibu-ibu anggota PKK. Kegiatan pengabdian yang telah dilakukan menjadikan ibu-ibu anggota PKK RT 03 RW XVI, Gendingan Kelurahan Jebres Kecamatan Jebres Kota Surakarta memiliki pengetahuan dan ketrampilan terkait urban farming, memiliki sarana prasarana urban farming sehingga dapat menerapkan urban farming di lingkungannya.
\end{abstract}

\begin{abstract}
One of the problems faced in providing food from production to urban households is limited land. This also happened in the city of Surakarta. PKK RT 03 RW XVI, Gendingan Jebres village, Jebres Subdistrict, Surakarta City is a group of women who live in densely populated settlements. The problem faced by households in fulfilling family food is dependence on purchases due to limited land for food production. One solution to overcome this problem is to develop urban agricultural activities to support food self-sufficiency. It's just that PKK members do not have knowledge of urban farming, how to apply it, and the infrastructure is limited. Therefore, this community service activity is carried out to solve this problem by conducting counseling and training on urban farming, providing assistance with production facilities in the form of seeds, seedlings, polybags, wall bags, pots, and planting media. In addition, there was also assistance in implementing urban farming for women members of the PKK. Community service activities that have been carried out have made women members of the PKK RT 03 RW XVI, Gendingan Jebres Village, Jebres subdistrict, Surakarta City have knowledge and skills related to urban farming, have urban farming infrastructure so they can implement urban farming in their environment.
\end{abstract}




\section{PENDAHULUAN}

Pangan merupakan kebutuhan pokok manusia yang pemenuhannya menjadi hak dasar setiap manusia. Kecukupan pangan menentukan kualitas sumberdaya manusia dan ketahanan bangsa (Suyastiri, 2008). Undang-Undang Republik Indonesia Nomor 18 Tahun 2012 tentang Pangan pada Bab 1 Pasal 1 ayat 3 menyatakan bahwa Kemandirian Pangan adalah kemampuan negara dan bangsa dalam memproduksi pangan yang beraneka ragam dari dalam negeri yang dapat menjamin pemenuhan kebutuhan Pangan yang cukup sampai di tingkat perseorangan dengan memanfaatkan potensi sumber daya alam, manusia, sosial, ekonomi, dan kearifan lokal secara bermartabat. Ketersediaan pangan rumah tangga dipengaruhi oleh produksi pangan dan pendapatan yang menentukan daya beli seseorang atau keluarga terhadap pangan. Status sosial budaya seperti sikap, kebiasaan makan, tabu terhadap makanan, ketidaktahuan akan gizi dan distribusi pangan dalam keluarga mempengaruhi kecukupan ketersediaan pangan (Rahayu, 2014).

Salah satu masalah yang dihadapi dalam penyediaan pangan dari produksi pada rumah tangga perkotaan adalah keterbatasan lahan. Hal ini juga terjadi di Kota Surakarta. Kabag Perekonomian Setda Surakarta, Sukendar, Rabu (9/10) mengatakan, "Merujuk data Badan Pertanahan Nasional, terdapat 135 hektare lahan pertanian di Surakarta pada 2013. Empat tahun berselang, menyusut menjadi 110 hektare. Pun tersisa 50an hektare di 2018". Hal ini berdampak pada ketergantungan penduduk Kota Surakarta kepada wilayah lain dalam peyediaan pangan rumah tangga. Kepala Bidang Penganekaragaman dan Keamanan DPLPP Surakarta, Wisnu Dwi Endro mengatakan bahwa untuk mencukupi komoditas pangan di Kota Solo masih mengandalkan pasokan dari daerah sekitar (Perdana, 2019).
Salah satu upaya yang dapat dilakukan untuk menyediakan pangan dari produksi di daerah perkotaan adalah dengan mengembangkan pertanian perkotaan (urban farming). Pertanian perkotaan didefinisikan sebagai produksi pangan yang terjadi di dalam batasbatas kota (Sampeliling et al., 2012). Produksi pangan tersebut terjadi di halaman belakang, di atap rumah, di kebun sayur dan buah komunitas dan di ruang publik atau tempat yang tidak digunakan. Pertanian kota mencakup juga kegiatan komersial yang menghasilkan pangan di rumah kaca dan di ruang terbuka, tetapi lebih sering berskala kecil dan tersebar di sekitar kota (Food and Agriculture Organization of the United Nations, 2006).

Pertanian perkotaan terbukti memiliki kapasitas untuk berkontribusi dalam penciptaan lapangan kerja dan penghasilan, ketahanan pangan, dan konservasi lingkungan (Cissé et al., 2005) Di Malaysia, pertanian perkotaan juga berperan dalam ketahanan pangan dengan menyediakan akses kepada penduduk kota pada makanan bergizi, aman, dapat diterima dan hemat biaya (Rezai et al., 2016). Peri-Urban Agriculture (PUA) di sekitar Jakarta serta di Timur dan Timur Laut Jabodetabek telah berkontribusi pada peningkatan keterjangkauan pangan serta memperkuat kebijakan ketahanan pangan (Pribadi \& Pauleit, 2016). Hasil pengabdian menunjukkan bahwa terjadi penambahan pengetahuan mengenai urban farming "vertikultur" dan mempraktekkannya. Penambahan pendapatan rumah tangga berupa pendapatan implisit yang berperan untuk menghemat anggaran pembelian sayuran sehingga anggaran tersebut dapat digunakan untuk keperluan lainnya yang bermanfaat (menambah kesejahteraan rumah tangga) (Wachdijono et al., 2019).

Salah satu dari 10 program pokok PKK adalah program yang ketiga yaitu pangan. Program ini berkaitan dengan pemberdayaan PKK agar rumah tangga anggota PKK 
mampu memenuhi pangan yang baik dari sisi kuantitas maupun kualitas (Hayati et al., 2017). Permasalahan yang dihadapi mitra adalah penyediaan pangan yang tergantung pada pembelian. Hal ini disebabkan keterbatasan lahan karena berada di lingkungan perkotaan yang padat penduduk sehingga tidak dapat menyediakan pangan dari produksi sendiri. Salah satu solusi untuk mengatasi masalah ini adalah dengan mengembangkan kegiatan urban farming untuk mendukung kemandirian pangan. Hanya saja ibu-ibu anggota PKK belum memiliki pengetahuan tentang urban farming, cara menerapkannya dan sarana prasarananya terbatas. Oleh karena itu, kegiatan pengabdian ini dilakukan untuk menyelesaikan masalah tersebut dengan melakukan penyuluhan, pelatihan, bantuan sarana prasarana, dan pendampingan penerapan urban farming pada ibu-ibu PKK RT 03 RW XVI, Gendingan Kelurahan Jebres Kecamatan Jebres Kota Surakarta.

\section{METODOLOGI}

Kegiatan pengabdian dilaksanakan di Kampung Gendingan Kelurahan Jebres Kecamatan Jebres Kota Surakarta. Mitra dalam kegiatan ini adalah ibu-ibu PKK RT 03 RW XVI, Gendingan Kelurahan Jebres Kecamatan Jebres Kota Surakarta. Kegiatan ini menggunakan beberapa metode yaitu penyuluhan, pelatihan, praktik, dan introduksi alat produksi. Pengabdian dilakukan dengan tahapan/ langkah-langkah pelaksanaan adalah sosialisasi, pelaksanaan kegiatan, monitoring dan evaluasi serta pendampingan.

1. Sosialisasi Kegiatan

a. Tim pelaksana mensosialisasikan rencana kegiatan kepada ketua PKK RT 03 RW XVI, Gendingan Kelurahan Jebres Kecamatan Jebres Kota Surakarta b. Tim pelaksana bersama dengan ketua PKK RT 03 RW XVI, Gendingan Kelurahan Jebres Kecamatan Jebres Kota Surakarta merencanakan pelaksanakan kegiatan yang meliputi tanggal, tempat, dan sarana yang diperlukan dalam pelaksanaan kegiatan. Hasil koordinasi menyepakati pelaksanaan pengabdian dilakukan pada hari Sabtu, tanggal 29 Agustus 2020 bertempat di gedung pertemuan warga Gendingan.

2. Penyuluhan tentang urban farming

a. Tim pelaksana berkoordinasi dengan mitra terkait dengan pelaksanaan penyuluhan urban farming

b. Tim menyiapkan penyuluh urban farming

c. Pelaksanaan penyuluhan terkait kepentingan dan manfaat urban farming dalam penyediaan pangan rumah tangga dan jenis-jenis teknik budidaya urban farming yang dapat diterapkan dilahan sempit perkotaan

3. Pelatihan dan praktek urban farming

a. Tim pelaksana berkoordinasi dengan mitra terkait dengan pelaksanaan pelatihan dan praktek urban farming

b. Tim menyiapkan pelatih urban farming

c. Pelaksanaan pelatihan urban farming yang meliputi penyiapan bibit, penyiapan media tanam, cara penanaman, pemeliharaan, sampai pemanenan dengan media penanaman pot, polibag, dan wallbag.

4. Tim melakukan pendampingan, monitoring, dan evaluasi implementasi dari pelatihan.

\section{HASIL DAN PEMBAHASAN}

Kegiatan pengabdian dilakukan pada hariSabtu, tanggal 29 Agustus 2020 bertempat di gedung pertemuan warga Gendingan. Kegiatan tidak diikuti oleh semua anggota 
PKK karena untuk memenuhi protokol Covid 19 dengan membatasi jumlah orang yang berkumpul sehingga peserta pelatian adalah perwakilan dari anggota PKK.

\section{Penyuluhan tentang Urban farming}

Penyuluhan dilaksanakan di Gedung Pertemuan warga Gendingan dengan memperhatikan protokol kesehatan yaitu dengan memakai masker, face shield, dan jaga jarak. Kegiatan ini diawali dengan sambutan oleh ketua tim pengabdian, Dr. Umi Barokah, S.P. M.P. Dalam sambutannya Dr. Umi Barokah menyampaikan latar belakang pelaksanaan pengabdian, tujuan, kegiatan yang dilaksanakan, dan harapan kepada mitra untuk dapat melaksanakan dan mengambil manfaat dari pelaksanaan kegiatan pengabdian. Kegiatan ini disambut baik oleh anggota PKK, berterima kasih kepada tim pengabdian dan bersedia untuk menerapkan apa yang diperoleh dari penyuluhan tentang urban farming. Hal ini disampaikan oleh ketua PKK RT 03 RW XVI, Gendingan Kelurahan Jebres Kecamatan Jebres Kota Surakarta dalam sambutannya.

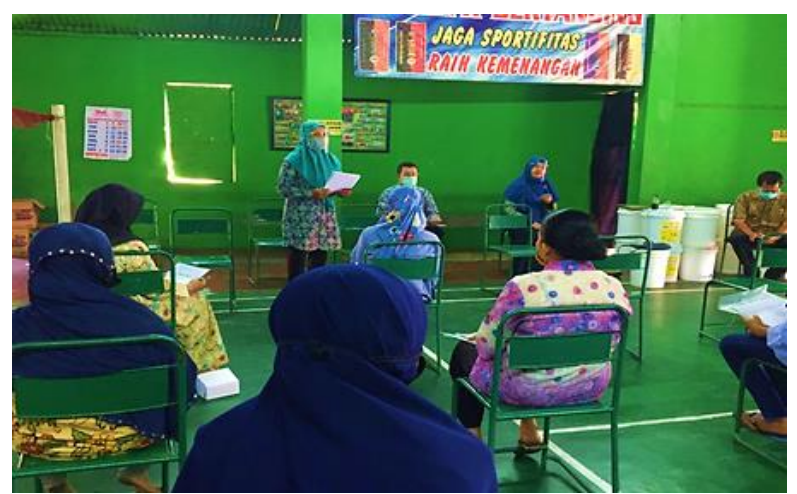

Gambar 1. Sambutan Ketua Tim Pengabdian

Penyuluhan tentang urban farming dilakukan untuk memberikan pemahaman kepada masyarakat tentang pengertian urban farming, manfaat urban farming khususnya manfaat untuk membantu rumah tangga dalam memenuhi kebutuhan pangan rumah tangga. Pada kegiatan ini juga dijelaskan cara penyimpanan sayuran dan penganekaragaman olahan sayuran. Penyuluhan dilakukan oleh petugas dari Studio Tani yang didatangkan oleh tim pengabdian.

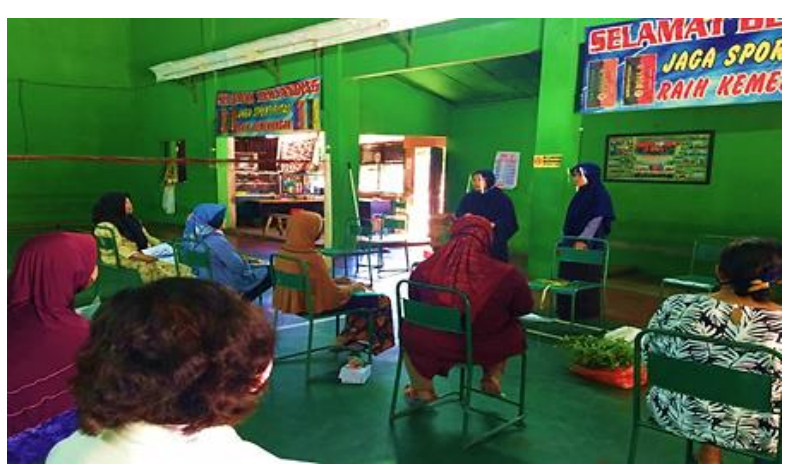

Gambar 2. Penyuluhan urban farming

\section{Pelatihan dan praktek urban farming}

Pelatihan dan praktek urban farming dilakukan dalam rangka membekali ibu-ibu anggota PKK untuk dapat melakukan urban farming yang pada kesempatan pengabdian ini berupa budidaya sayuran di pekarangan dengan menggunakan polibag, wallbag, dan pot. Pelatihan diawali dengan penjelasan mengenai tahaptahap budidaya tanaman sayuran baik sayuran daun seperti sawi, kangkung, bayam dan sayuran buah seperti cabe dan terong. Penjelasan meliputi cara pembuatan media tanam, pembibitan, pindah tanam, pemeliharan (pemupukan dan pemberantasan hama), pemanenan, dan pengananan pasca panen. Pelatih juga menyampaikan pemanfaatan barang bekas untuk media tanam. Sebelum dilakukan praktek, diadakan diskusi terlebih dahulu. Peserta pelatihan bersemangat mengikuti pelatihan dan aktif dalam diskusi. Kegiatan diakhiri dengan praktek menanam.

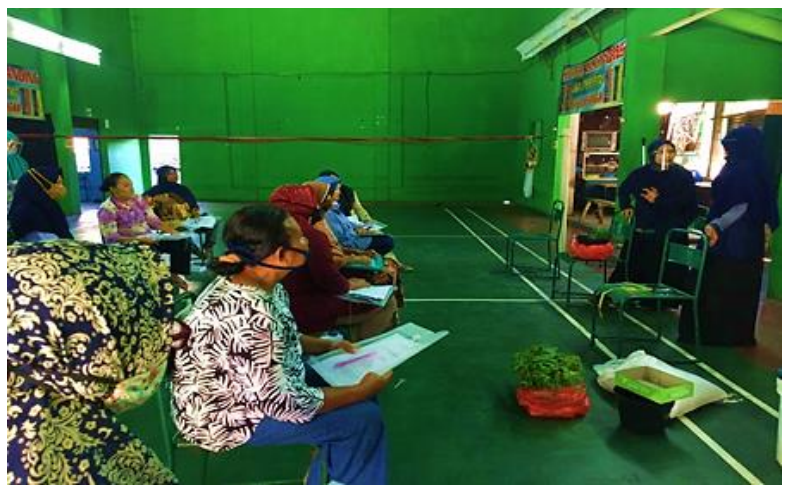

Gambar 3. Pelatihan Urban farming 


\section{Introduksi Sarana produksi}

Untuk menunjang implementasi dari penyuluhan dan pelatihan urban farming maka pada kegiatan pengabdian ini diberikan bantuan sarana produksi. Sarana produksi yang diberikan berupa benih (bayam dan kangkung), bibit (terong, cabai, tomat), bibit lele, polibag, wallbag, pot, dan media tanam. Bantuan sarana produksi ini diberikan kepada semua anggota PKK. Peralatan diserahkan oleh tim pengabdian dan diterima oleh ketua PKK RT 03 RW XVI, Gendingan Kelurahan Jebres Kecamatan Jebres Kota Surakarta. Kegiatan introduksi peralatan produksi disajikan pada Gambar 4.

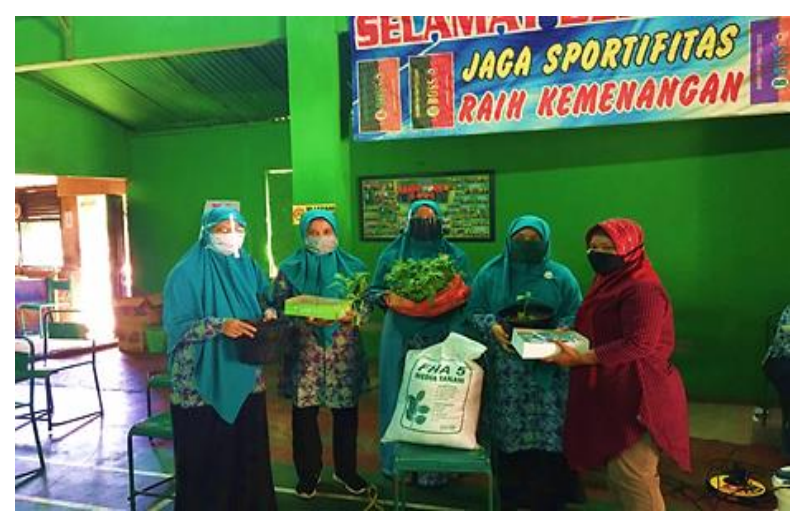

Gambar 4. Penyerahan Bantuan Sarana Produksi

Dengan introduksi sarana produksi ini diharapkan anggota PKK dapat termotivasi untuk menerapkan hasil pelatihan yaitu melakukan budidaya tanaman sayuran di sekitar rumah untuk menunjang kemandirian pangan rumah tangga. Kegiatan pengabdian diakhiri dengan foto bersama peserta pelatihan dengan tim pengabdian.

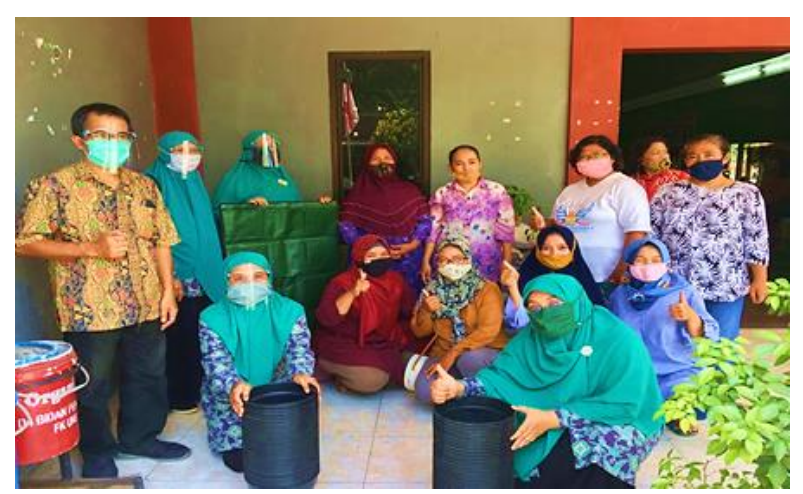

Gambar 5. Foto bersama Tim Pengabdian dan Peserta Pelatihan

\section{Monitoring dan Evaluasi}

Kegiatan monitoring dan evaluasi dilakukan untuk memonitoring implementasi pelatihan urban farming yang telah dilakukan. Monitoring dilakukan secara daring melalui komunikasi dengan ketua PKK dan datang langsung kepada anggota PKK. Monitoring awal menunjukkan peserta pelatihan mengimplementasikan hasil pelatihan dengan mulai melakukan budidaya tanaman sayuran dengan memanfaatkan sarana produksi yang diintroduksikan tim pengabdian (Gambar 6 dan 7). Ibu-ibu anggota PKK juga berkreasi dengan memanfaatkan barang-barang bekas seperti kaleng bekas untuk menanam sayuran (Gambar 8).

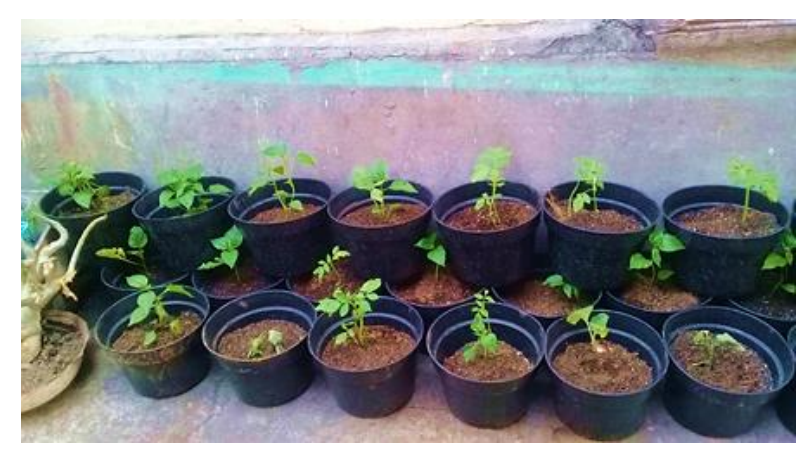

Gambar 6. Penanaman Sayuran di Pot

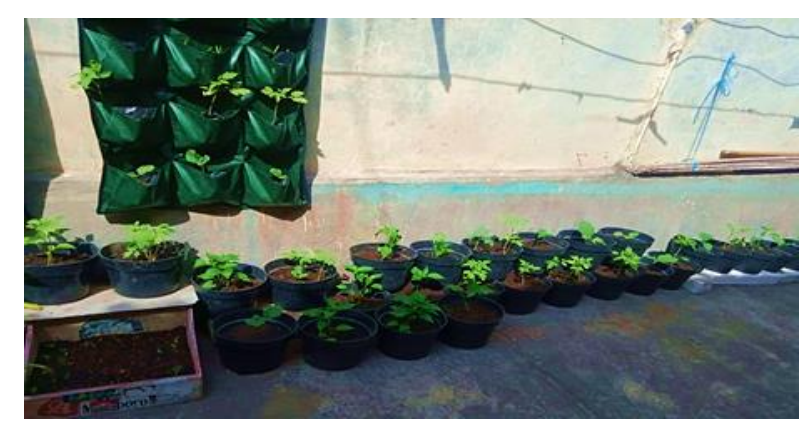

Gambar 7. Penanaman Sayuran di Wallbag

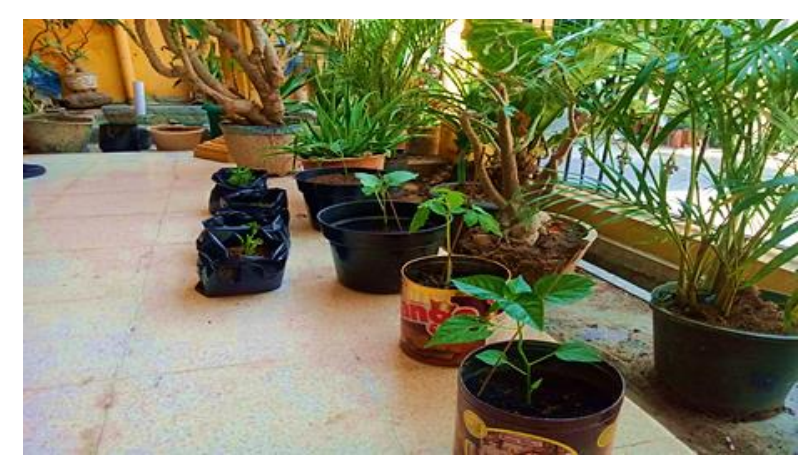

Gambar 8. Penanaman Sayuran di Kaleng Bekas 


\section{KESIMPULAN}

Kegiatan pengabdian yang telah dilakukan menjadikan ibu-ibu anggota PKK RT 03 RW XVI, Gendingan Kelurahan Jebres Kecamatan Jebres Kota Surakarta memiliki pengetahuan dan ketrampilan terkait urban farming, memiliki sarana prasarana urban farming sehingga dapat menerapkan urban farming di lingkungannya. Ibu-ibu anggota PKK juga berkreasi memanfaatkan barang bekas untuk menanam sayuran. Pendampingan sebaiknya senantiasa dilakukan oleh tim pengabdian agar kegiatan urban farming yang telah dirintis dapat berkelanjutan sehingga dapat membantu rumah tangga dalam mewujudkan kemandirian pangan.

\section{UCAPAN TERIMA KASIH}

Terima kasih diucapkan Kepada Lembaga Penelitian dan Pengabdian kepada Masyarakat (LPPM) UNS atas dukungan dana pelaksanaan kegiatan pengabdian ini dan Ibu-ibu anggota PKK RT 03 RW XVI, Gendingan Kelurahan Jebres Kecamatan Jebres Kota Surakarta yang telah bersedia menjadi mitra dan berpartisipasi aktif sehingga kegiatan pengabdian berjaan lancar.

\section{REFERENSI}

Cissé, O., Gueye N.F.D., Sy, M. 2005. Institutional and legal aspects of urban agriculture in Frenchspeaking West Africa: from marginalization to legitimization. Environment and Urbanization. 17(2):143-154.

https://doi.org/10.1177/09562478050170021 1

Food and Agriculture Organization of the United Nations. 2006. The State of Food and Agriculture. FAO Agriculture Series No. 37. Rome: Food and Agriculture Organization of the United Nations.

Hayati, F.K., Irja, D., Natuna, D.A. 2017. Analisis Pelaksanaan 10 Program Pokok Pemberdayaan Kesejahteraan Keluarga (PKK)
Di Desa Sukadamai Kecamatan Ujungbatu Kabupaten Rokan Hulu. JOM FKIP Universitas Riau. 4(1):1-12.

Perdana. 2019. Solo Wujudkan Kota Cerdas Pangan di Lahan Terbatas.

https://radarsolo.jawapos.com/read/2019/0 1/31/117028/solo-wujudkan-kota-cerdaspangan-di-lahan-terbatas

Pribadi, D.O., Pauleit, S. 2016. Peri-urban agriculture in Jabodetabek Metropolitan Area and its relationship with the urban socioeconomic system. Land Use Policy. 55:265-274. doi: https://doi.org/10.1016/j.landusepol.2016.04 .008

Rahayu, W. 2014. Ketersediaan Pangan Pokok Pada Rumah Tangga Petani Padi Sawah Irigasi Dan Tadah Hujan Di Kabupaten Karanganyar. Jurnal Sosial Ekonomi Pertanian (J-SEP). 7(1):4551.

Rezai, G., Shamsudin, M.N., Mohamed, Z. 2016. Urban Agriculture: A Way Forward to Food and Nutrition Security in Malaysia. Procedia - Social and Behavioral Sciences. 216:39-45. https://doi.org/10.1016/j.sbspro.2015.12.006

Sampeliling, S., Sitorus, S.R.P., Nurisyah, S., Pramudya, B. 2012. Kebijakan Pengembangan Pertanian Kota Berkelanjutan: Studi Kasus Di DKI Jakarta. Analisis Kebijakan Pertanian. 10(3):257267.

http://dx.doi.org/10.21082/akp.v10n3.2012.2 $57-267$

Suyastiri, N.M. 2008. Diversifikasi Konsumsi Pangan Pokok Berbasis Potensi Lokal Dalam Mewujudkan Ketahanan Pangan Rumahtangga Pedesaan Di Kecamatan Semin Kabupaten Gunung Kidul. Economic Journal of Emerging Markets. 13(1):51-60. https://doi.org/10.20885/vol13iss1aa50

Wachdijono, W., Wahyuni, S., Trisnaningsih, U. 2019. Penerapan Urban Farming "Vertikultur" untuk Menambah Pendapatan Rumah Tangga di Kelurahan Kalijaga Kecamatan Harjamukti Kota Cirebon. In Prosiding Seminar Nasional UNIMUS. Semarang: Universitas Muhammadiyah Semarang. 2:374-381. 